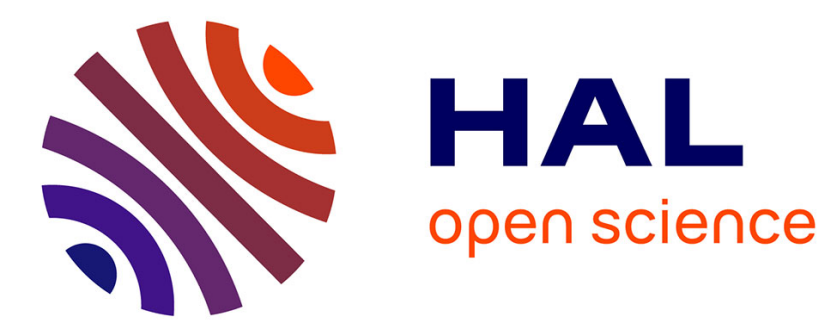

\title{
Ovarian response to stimulation for fertility preservation in women with hematologic cancer
}

Tiffany Brun, Ludivine Dion, Sylvie Jaillard, Diane Bales, Mathilde Domin, Vincent Vincent.Lavoue@chu-Rennes.Fr Lavoué, Jean Lévêque, Roch Houot, Solène Duros

\section{To cite this version:}

Tiffany Brun, Ludivine Dion, Sylvie Jaillard, Diane Bales, Mathilde Domin, et al.. Ovarian response to stimulation for fertility preservation in women with hematologic cancer. Journal of Gynecology Obstetrics and Human Reproduction, 2021, 50 (5), pp.101925. 10.1016/j.jogoh.2020.101925 . hal02964534

\section{HAL Id: hal-02964534 \\ https://hal.science/hal-02964534}

Submitted on 19 Nov 2020

HAL is a multi-disciplinary open access archive for the deposit and dissemination of scientific research documents, whether they are published or not. The documents may come from teaching and research institutions in France or abroad, or from public or private research centers.
L'archive ouverte pluridisciplinaire $\mathbf{H A L}$, est destinée au dépôt et à la diffusion de documents scientifiques de niveau recherche, publiés ou non, émanant des établissements d'enseignement et de recherche français ou étrangers, des laboratoires publics ou privés. 


\section{Ovarian response to stimulation for fertility preservation in women with hematologic cancer}

Tiffany Brun ${ }^{1 *}$, Ludivine Dion ${ }^{1}$, Sylvie Jaillard ${ }^{2,3}$, Diane Bales ${ }^{1}$, Mathilde Domin ${ }^{1}$, Vincent Lavoué ${ }^{1,4}$, Jean Levêque ${ }^{1,4}$, Roch Houot ${ }^{5,6}$, Solène Duros ${ }^{1}$

${ }^{1}$ CHU Rennes, Département de Gynécologie Obstétrique et Reproduction Humaine, F-35033, Rennes, France

${ }^{2}$ CHU Rennes, Service de Cytogénétique et Biologie Cellulaire, F-35033, Rennes, France

${ }^{3}$ Univ Rennes, CHU Rennes, INSERM, EHESP, IRSET (Institut de recherche en santé, environnement et travail) - UMR_S 1085, F-35000, Rennes, France

${ }^{4}$ Univ Rennes INSERM UMR 1242, F-35000 Rennes, France

${ }^{5}$ CHU Rennes, Service Hématologie Clinique, Rennes, France

${ }^{6}$ Univ Rennes, CHU Rennes MICMAC-Inserm UMR 1236, F-35000 Rennes, France

*br.tiffany@ outlook.fr

\section{$\underline{\text { Abstract }}$}

Purpose: To compare the ovarian response to controlled ovarian hyperstimulation $(\mathrm{COH})$ in patients with hematologic malignancies treated for fertility preservation (FP) and healthy subjects (oocyte donors (OD)).

Patients and Methods: Retrospective cohort study comparing 41 women (18-37 years) who underwent $\mathrm{COH}$ for oocyte vitrification prior to gonadotoxic treatment for hematologic cancer (FP group) from January 2014 to February 2019 and with 117 women undergoing COH as part of an OD protocol (OD group) during the same period. The number of frozen mature oocytes, number of oocytes retrieved, total dose of rFSH, maximal estradiol levels, percentage of maturity, number of dominant follicles $>14 \mathrm{~mm}$, days of stimulation were evaluated. Results were adjusted for age, body mass index (BMI), antiMullerian hormone (AMH) and $\mathrm{rFSH}$ starting dose.

Results: Patients in the FP group were younger and had a lower BMI than those in the OD group. rFSH starting dose was higher in the FP group (median 225UI $(125 ; 450)$ vs $150 \mathrm{UI}(87.5 ; 337.5), \mathrm{p}<0.0001)$. After adjusting for age, BMI and starting rFSH dose according to ANCOVA, more frozen mature oocytes (median $10(0 ; 45)$ vs $8(0 ; 22) \mathrm{p}=0.0055)$ and retrieved oocytes (median $12(0 ; 49)$ vs $11(0 ; 29)$ $\mathrm{p}=0.0468$ ) were found in the FP group. Other outcome measures did not differ between the groups.

Conclusion: Ovarian response after $\mathrm{COH}$ in women with a hematologic cancer is similar to that in the general population. A higher number of mature oocytes were collected in the FP group after strong $\mathrm{COH}$. 


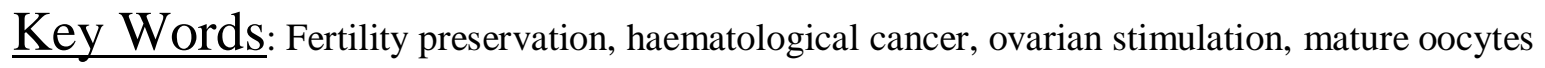

\section{$\underline{\text { Introduction }}$}

Hematologic malignancies affect more than 35,000 people each year in France including young adults of reproductive age (1). Advances in the management of oncological diseases have increased the life expectancy and survival rate in young patients (2).

However, treatments like chemotherapy and radiotherapy used to cure malignancies have a negative impact on a woman's fertility, either temporarily or permanently, by altering the ovarian function. Indeed, chemotherapy for hematologic malignancies are gonadotoxic by damaging primordial, preantral and antral follicles by apoptical process (3). In addition, delaying the pregnancy project during the treatment and remission periods can also impact fertility because of physiological follicular loss.

The question of fertility preservation (FP) in young cancer patients has become an important component in the management of cancer patients today (4). Many FP techniques have been developed to improve the chances of young cancer survivors to become genetic parents after treatment. Among these, controlled ovarian hyperstimulation $(\mathrm{COH})$ before the gonadotoxic treatment followed by oocyte cryopreservation is currently the most common and effective technique.

It has been suggested that the oncological status in itself could have a negative impact on ovarian function. The methodologies and populations of studies investigating the response to $\mathrm{COH}$ in cancer patients are varied and results differ: some have found that a lower ovarian response to $\mathrm{COH}$ in women suffering from malignancies $(5,6)$ while others have found no significant difference in response (7-9). Only two studies have focused on hematologic cancers and both found a lower response to $\mathrm{COH}$ compared to patients with breast cancer and healthy populations $(10,11)$.

Overall, ovarian stimulation outcomes in hematologic cancer patients have not been adequately investigated. Moreover, in these studies, the control population are infertile couples or patients with other cancers. The aim of this study was to compare the ovarian response to $\mathrm{COH}$ in patients with specific hematologic malignancies treated for FP and a healthy population of oocyte donors (OD). 


\section{Materials and Methods}

\section{Study Population}

A retropective single-center analysis was performed between January 2014 and February 2019 in the Center of Reproductive Medicine at Rennes University Hospital. All women between 18-37 years of age who had $\mathrm{COH}$ for oocyte vitrification because of a hematologic cancer before undergoing treatment with gonadotoxic agents (chemotherapy or radiotherapy) were included (FP group).

The inclusion criteria were as follows: (i) regular menstrual cycles lasting between 25 and 35 days; (ii) both ovaries present, with no morphological abnormalities (such as cysts, endometriomas, etc.), and satisfactorily visualized by transvaginal ultrasound scan; (iii) an antral follicle count (AFC) $\geq 5$; (iv) oncologist approval for $\mathrm{COH}$. Any patients with current or past diseases affecting the ovaries or gonadotropin or sex steroid secretion, clearance, or excretion, were not included. Exclusion criteria were: (i) patients with an $\mathrm{AFC}<5$, who were not eligible for oocyte vitrification after $\mathrm{COH}$ due to poor expected ovarian response; (ii) a history of oophorectomy or gonadotoxic treatment.

$\mathrm{COH}$ outcomes obtained in the FP group were compared with those of 117 healthy oocyte donors (OD group) during the same period. $\mathrm{COH}$ for both populations were performed in the same centre, during the same time frame, and meeting similar inclusion and exclusion criteria.

This study was approved by the Ethics Committee of Rennes University Hospital on 04/04/2019 (Reference $\mathrm{n}^{\circ}$ 19.35) and data collection was declared to the National Commission for Data Protection (CNIL).

\section{$\underline{\text { Stimulation protocol }}$}

Ovarian stimulation was performed using a GnRH antagonist protocol and administration of exogenous recombinant-follicle stimulating hormone (rFSH; Gonal- $\mathrm{F}^{\circledR}$, Merck-Serono Pharmaceuticals, France or Puregon $^{\circledR}$, Pharmaceuticals, MSD, France, Bemfola ${ }^{\circledR}$, Gedeon Richter France). rFSH therapy was initiated at a dosage ranging from 150 to 450 IU/day, according to the patient's age, body mass index (BMI), and AFC.

Candidates for oocyte donation underwent baseline hormonal and ultrasonographic assessment, either on cycle day 2 or 3 of a spontaneous cycle. rFSH was administered at an initial dosage for at least 5 days after which the daily rFSH doses were adjusted according to estradiol $\left(\mathrm{E}_{2}\right)$ levels and/or the number of growing follicles. Starting on stimulation day 6 , all patients received $0.25 \mathrm{mg}$ of a GnRH antagonist (Ganirelix, Orgalutran ${ }^{\circledR} 0.25$ mg MSD, France, Fyramedel ${ }^{\circledR}$ Ferring, France). 
Since FP often requires emergency treatment, the first evaluation in the FP group was randomly performed during the early follicular, late follicular or luteal phase of the cycle as determined by serum progesterone levels and $\mathrm{AFC}(12,13)$. If the $\mathrm{COH}$ was performed during the early follicular phase (serum progesterone levels $<1.5 \mathrm{ng} / \mathrm{mL}$ and absence of antral follicle $>12 \mathrm{~mm}$ in diameter on ultrasound scan), the protocol was similar to that used in the OD group. If the $\mathrm{COH}$ was performed during the late follicular phase (serum progesterone levels $<1.5 \mathrm{ng} / \mathrm{mL}$ and the presence of a selected antral follicle measuring $>12 \mathrm{~mm}$ in diameter) ovulation was triggered by human chorionic gonadotropin (hCG, Ovitrelle $^{\circledR} 250$ mcg; Merck-Serono Pharmaceuticals, 0.25 mg S.C.). Hormonal-follicular evaluation (baseline) was scheduled 3 days later and rFSH administration was started on confirmation of the luteal phase (serum progesterone levels $>3.0 \mathrm{ng} / \mathrm{mL}$ and presence of a corpus luteum). Finally, if $\mathrm{COH}$ was initiated during the luteal phase (serum progesterone levels $>3.0 \mathrm{ng} / \mathrm{mL}$ ), $\mathrm{rFSH}$ was administered in combination with a GnRH antagonist for 5 days and adjusted according to $\mathrm{E}_{2}$ levels and/or the number of growing follicles.

In all patients, supplementation of luteinizing hormone ( $\mathrm{LH})$ activity for final oocyte maturation was provided by either recombinant-hCG (Ovitrelle ${ }^{\circledR} 250 \mathrm{mcg}$; Merck-Serono Pharmaceuticals, $0.25 \mathrm{mg}$ S.C.) or GnRH agonists (Decapeptyl ${ }^{\circledR}$, Ipsen Pharma, France, $0.2 \mathrm{mg}$, S.C.), as soon as $\geq 3$ preovulatory follicles (16-22 $\mathrm{mm}$ in diameter) were observed and $\mathrm{E}_{2}$ levels per preovulatory follicle were >200 $\mathrm{pg} / \mathrm{mL}$. GnRH agonists were used as trigger in GnRH antagonist protocol if we had more than 18 follicles larger than $11 \mathrm{~mm}$. Oocytes were retrieved by transvaginal ultrasound-guided aspiration, 35 hours after ovulation triggering (dOT).

No patients were administered aromatase inhibitors or anti-estrogen therapy during $\mathrm{COH}$.

Mature oocytes, documented by the presence of one pronucleus, were vitrified as previously described (14).

\section{Outcome measures}

The primary outcome measure was the number of oocytes retrieved. Secondary outcome measures included the number of mature oocytes frozen, duration of stimulation (days), total dose of gonadotropin used, maximum $\mathrm{E}_{2}$ level, number of follicles $>14 \mathrm{~mm}$ on dOT, maturity ratio (number of mature oocytes vitrified / collected) and the ratio of mature oocytes / number of follicles $>14 \mathrm{~mm}$.

\section{Hormonal measurements}

Serum levels of progesterone $(\mathrm{ng} / \mathrm{mL}), \mathrm{E}_{2}(\mathrm{ng} / \mathrm{mL})$ and $\mathrm{LH}(\mathrm{mIU} / \mathrm{mL})$ were assessed by an automated multi-analysis system using a chemiluminescence technique (COBAS 8000 modular analyzer - Roche 
Diagnostics France). For progesterone (CLIA technique), the limit of detection was $0.10 \mathrm{ng} / \mathrm{mL}$, and the coefficient of variation (CV) was 6.2\%. For $\mathrm{E}_{2}$ (CLIA technique), the limit of detection was 17.52 $\mathrm{pg} / \mathrm{mL}$, linearity up to $3326.00 \mathrm{pg} / \mathrm{mL}$, and $\mathrm{CV}$ was $8.6 \%$. For LH (ICMA technique), the limit of detection was $0.4 \mathrm{mIU} / \mathrm{mL}$, and $\mathrm{CV}$ was $3.1 \%$ (15).

\section{$\underline{\text { Statistical analyses }}$}

Clinical and biological data were collected from a data extraction MediFirst-AMP software (version 1.4, Company MEDIFIRST France). Differences between the FP and OD groups were evaluated with the Mann-Whitney Wilcoxon's test. Results were adjusted on age, BMI, AMH value, and baseline rFSH by an ANCOVA. A P value $<0.05$ was considered statistically significant. Statistical analyses were performed using SAS V9 software. 4.

\section{$\underline{\text { Results }}$}

\section{Patient characteristics}

Between January 2014 and February 2019, 73 patients with a hematologic cancer were referred to the Centre of Reproductive Medicine at Rennes Hospital for FP counselling. Fourteen had already had chemotherapy: 10 had relapsed, three had ovarian failure after gonadotoxic treatment, and one had started chemotherapy after in vitro maturation that did result in a mature oocyte and consulted for ovarian cortex removal. Fifty-nine patients consulted before starting chemotherapy: 45 received ovarian stimulation and 4 were excluded because they were $<18$ years. Finally, 41 patients who underwent $\mathrm{COH}$ before starting a gonadotoxic treatment were included in the study (figure 1). They were grouped according to the hematologic cancer type and chemotherapy protocol administered (Table 1).

Table 2 summarizes the patient characteristics. Patients in the PF group were significantly younger and had a lower BMI than those in the OD group (median 24 years $(18 ; 37)$ vs $33(2 ; 38)$, respectively, $\mathrm{p}<0.0001$ and $21.48 \mathrm{~kg} / \mathrm{m}^{2}(16 ; 45)$ vs $\left.23.4(16 ; 40.1) \mathrm{p}=0.0219\right)$. Exogenous rFSH starting dose was also significantly higher in the FP group (225UI $(125 ; 450)$ vs $150(87.5 ; 337.5)$, respectively, $p<0.0001)$. Baseline AFC and AMH were similar in the two groups. Twenty-three patients in the PF group started the stimulation in the early follicular phase, nine in the late follicular phase and nine in the luteal phase. Final oocyte maturation was provided using rhCG for 15 patients in the FP group (36.6\%) and 47 in the OD group (40.2\%). GnRH agonists was used by 26 patients in the PF group (63.4\%) and 70 in the OD group (59.8\%). All COH protocols resulted in oocyte retrieval. 


\section{$\underline{\text { COH characteristics and outcomes }}$}

Table 3 summarizes the ovarian response in the two groups. After adjusting for age, sex, BMI and starting rFSH dose according to ANCOVA, a significant difference was found between the FP and OD groups in the number of oocytes retrieved $(12(0 ; 49)$ vs $11(0 ; 29)$, respectively, $\mathrm{p}=0.0468)$ and the number of frozen mature oocytes $(10(0 ; 45)$ vs $8(0 ; 22)$, respectively, $\mathrm{p}=0.0055)$. Median total amount of exogenous $\mathrm{rFSH}$ administered, maximum $\mathrm{E}_{2}$ level on the dOt and number of dominant follicles $>14 \mathrm{~mm}$, duration of ovarian stimulation, and the percentage of maturity were comparable in both groups.

No cases of ovarian hyperstimulation syndrome (OHSS) were reported in either group.

\section{Discussion}

This retrospective study comparing ovarian response following $\mathrm{COH}$ in women with hematologic malignancies with that in a healthy population of oocyte donors, found that there was no difference in ovarian response to gonatropins and that a higher number of mature oocytes was retrieved and vitrified in the group of women undergoing $\mathrm{COH}$ for FP. The results were adjusted for age, BMI, AMH, and baseline rFSH dose.

Following improvements in hematologic malignancy management, FP has become a major issue. Surprisingly, a significantly higher number of oocytes were reported in the FP group than in the OD group. This could be explained by the relatively high number of young patients in the FP group who had a large number of oocytes collected and vitrified: e.g., 49 oocytes collected, 45 of which were vitrified. In view of the small number of study patients, these results have a strong influence on the average. However, we chose to use the median rather than the mean which would seems more relevant because because it does not take into account these extreme values.

The starting dose of rFSH was significantly higher in the FP group. This reflects a clinical consensus to administer a higher initial gonadotropin dose at the start of stimulation to promote maximum initial follicular recruitment in the context of FP as, in most cases, only one cycle of stimulation is possible before gonadotoxic treatment. The objective is to freeze as many oocytes as possible because the chances of pregnancy depend on the number of vitrified oocytes (16). The risk of OHSS is mitigated by the use of non-agonist GnRH triggering (17). In contrast, in the context of OD, a high yield is less important and the risk of side effects related to a high dose of rFSH (pain, OHSS...) must be taken into account.

The median total amount of exogenous rFSH administered and number of days of ovarian stimulation were comparable in both groups after adjusting for baseline dose and ovarian reserve characteristics (age, $A M H$ and BMH). 
In the literature, the results about the response of oncological patients to $\mathrm{COH}$ remain controversial (Supplementary Table 1). Some studies have suggested that the cancer itself could affect the reproductive system as it is associated with malnutrition, weight loss and an increased catabolism, which can affect the hypothalamic-pituitary axis and impair reproductive capacity. Some studies have also suggested that pro-inflammatory cytokines produced by tumor tissue may also impair fertility $(18,19)$. Therefore, the potential effect of malignancy on gonadal function through ovarian reserve and ovarian response to stimulation has been a subject of investigation. Friedler et al. performed a meta-analysis (6) of seven studies including a total of 227 women with cancer who had $\mathrm{COH}$ for FP. This study showed a poorer ovarian response compared to woman undergoing $\mathrm{COH}$ because of male infertility $(11.7 \pm 7.5$ vs $13.5 \pm 8.4$, respectively, $\mathrm{p}=.0027)$. Similarly, Domingo et al. (64) found that fewer mature oocytes were retrieved in 233 patients with cancer than in woman requiring stimulation because of male infertility (10.5 vs 12.4 , respectively, $\mathrm{p}=0.02)$. On the contrary, the studies by Das et al. (20) (41 women), Almog et al. (9) (81 women), and RB. Quintero et al. (21) did not find significant differences in the number of oocytes retrieved compared to a control group (male infertility). Similarly, the prospective study by C Decanter et al. (8) found lower AMH and fewer mature oocytes in their cancer patients. While the number of oocytes was similar in women with breast cancer or hematologic cancers, the total amount of exogenous rFSH administered and duration of ovarian stimulation was higher for the patients with hematologic cancer. Few studies have analyzed the results of ovarian stimulation specifically in patients with hematologic cancer. B. Lawrenz et al. (10) specifically studied patients with lymphoma and found lower AMH levels in these women compared to volunteers matched for age and BMI. However, the number of oocytes retrieved was lower than that in breast cancer patients without matching, whereas they were significantly younger. Alvarez et al. (22) studied 306 women with different cancers, including 76 with hematologic diseases, and found a lower number of oocytes in 34 women with gynecologic cancer compared to hematologic and breast cancers. However, they did not adjust for age, although the breast cancer patients were significantly older. The number of days of stimulation was greater for hematologic malignancies. Sonigo et al studied the follicular output rate (FORT), who is evaluation of antral follicle responsiveness to exogenous FSH, independently of the follicular cohort size before treatment. They found that the percentage of antral follicles that respond to FSH administration is reduced in HL when compared to BC patients. Finally, the largest study including 992 cycles of ovarian stimulation in cancer patients conducted by M. von Wolff et al. (23) found no difference between the different cancer groups in the number of oocytes retrieved after adjustment for age apart from the ovarian cancer group. The number of days of stimulation and total dose of rFSH were higher for patients with lymphoma.

The main limitations of our study are due to its retrospective, single-center nature. However, it would require many years to conduct a prospective analysis due to the small number of patients. In addition, group matching for age, BMI and AMH was not possible: very few donors were under 30 years old and 
very few patients with a hematologic malignancy in the FP group were over 30 years old. To overcome this bias, we chose to adjust our results on these criteria, as well as that of the starting dose of rFSH. It should also be noted that while all the patients had the same antagonist $\mathrm{COH}$ protocol, the patients in the FP group started treatment at different phases of the cycle. However, it has previously been shown that the number of oocytes retrieved is comparable regardless of the initial phase of stimulation (24). Our study is also limited by the small sample size (41 patients) as we only included women with hematologic malignancies. However, in contrast to larger studies, this allowed us to gather a lot of specific information about ovarian stimulation in this setting. For example in the study reported by Wolff T. Bruckner et al. (23), the data retrieved from the register did not allow for detailed analysis and the evaluation was limited to the number of oocytes, the duration of the stimulation (days) and the total dose of gonadotropins. The results were adjusted for age but not for ovarian reserve data such as AMH because these data were not available.

The main strength of our study is that we focused on hematologic malignancies allowing a more targeted analysis of this population, in contrast to subgroup analyses for which the control group is less relevant. Moreover, we chose a control population of OD because these women do not have fertility disorders or $\mathrm{COH}$ antecedents, unlike the control patients derived from assisted reproductive technology protocols used in many studies. An advantage of a single-center study in this context was that all the patients underwent the same approach to $\mathrm{COH}$ and the same laboratory was used for analyses: our patients all had antagonist stimulation, unlike other studies where different stimulation protocols were used. Thus, homogeneity of the $\mathrm{COH}$ protocol, monitoring, patient data and laboratory techniques is strength of our study. Our results could be further strengthened by reporting embryo development and pregnancy rates but unfortunately this was not possible as most women included in our population did not have medical approval for pregnancy.

Compared with other studies, the total amount of exogenous rFSH administered and the number of days of ovarian stimulation seems higher in our study, but more oocytes were retrieved. The encouraging rate of mature oocyte retrieval we observed in our study may be due to a stronger stimulation protocol in view of the lower $\mathrm{COH}$ results experienced by other teams. Indeed, it appears that the use of large doses of FSH is essential in the context of haematological cancers.

\section{Conclusion}

In conclusion, our results, adjusted for ovarian reserve, suggest that hematologic cancer does not affect ovarian response to $\mathrm{COH}$ compared to a healthy control population. This is in contrast to findings in previous studies reporting lower response rates but which mostly included all types of cancer and control groups either of women with other cancers or infertile patients. 
Thus, our results underline the interest of starting $\mathrm{COH}$ by high doses of $\mathrm{rFSH}$, in an antagonist protocol triggered by an agonist of GnRH to avoid OHSS and optimize the chances of a future pregnancy by optimal oocyte collection. These results are encouraging for patients in the process of preserving fertility before gonadotoxic therapy and could be used to reassure them about the good outcomes of ovarian stimulation for FP.

However, a larger, prospective, multicenter study is needed matching age, BMI and baseline rFSH dose with healthy controls.

Furthermore, a study with a long-term follow-up of our patients would be valuable to fully explore the effectiveness of this technique.

\section{Declarations:}

- Funding : Not applicable

- Conflicts of interest/Competing interests : The authors declare that they have no conflict of interest

- Ethics approval : Approval was obtained from the ethics committee of Rennes University Hospital on 04/04/2019 (Reference $n^{\circ} 19.35$ ).

- Consent to participate : Verbal informed consent was obtained for use data. Opposition to the use of data was notified in the medical file

- Consent for publication : Not applicable

- Availability of data and material : Yes

- Code availability : Yes

\section{References}

[1] Alain Monnereau, Laurent Remontet, Marc Maynadié, Florence Binder-Foucard, Aurélien Belot, Xavier Troussard, et al. National estimate of cancer's incidence in France. Part 2 - Hematologic malignancies - Summary. France: InVS, INCa; 2013 sept p. 3- 4.

[2] Siegel RL, Miller KD, Jemal A. Cancer statistics, 2015. CA Cancer J Clin. févr 2015;65(1):5 - 29.

[3] Fleischer RT, Vollenhoven BJ, Weston GC. The effects of chemotherapy and radiotherapy on fertility in premenopausal women. Obstet Gynecol Surv. avr 2011;66(4):248- 54.

[4] Practice Committee of American Society for Reproductive Medicine. Fertility preservation in patients undergoing gonadotoxic therapy or gonadectomy: a committee opinion. Fertil Steril. nov 2013;100(5):1214- 23.

[5] Domingo J, Guillén V, Ayllón Y, Martínez M, Muñoz E, Pellicer A, et al. Ovarian response to controlled ovarian hyperstimulation in cancer patients is diminished even before oncological treatment. Fertil Steril. avr 2012;97(4):930- 4. 
[6] Friedler S, Koc O, Gidoni Y, Raziel A, Ron-El R. Ovarian response to stimulation for fertility preservation in women with malignant disease: a systematic review and meta-analysis. Fertil Steril. janv 2012;97(1):125- 33.

[7] Lefebvre T, Mirallié S, Leperlier F, Reignier A, Barrière P, Fréour T. Ovarian reserve and response to stimulation in women undergoing fertility preservation according to malignancy type. Reprod Biomed Online. août 2018;37(2):201 - 7.

[8] Decanter C, Robin G, Mailliez A, Sigala J, Morschhauser F, Ramdane N, et al. Prospective assessment of follicular growth and the oocyte cohort after ovarian stimulation for fertility preservation in 90 cancer patients versus 180 matched controls. Reprod Biomed Online. mai 2018;36(5):543- 51.

[9] Almog B, Azem F, Gordon D, Pauzner D, Amit A, Barkan G, et al. Effects of cancer on ovarian response in controlled ovarian stimulation for fertility preservation. Fertil Steril. oct 2012;98(4):957- 60.

[10] Lawrenz B, Fehm T, von Wolff M, Soekler M, Huebner S, Henes J, et al. Reduced pretreatment ovarian reserve in premenopausal female patients with Hodgkin lymphoma or non-Hodgkinlymphoma - evaluation by using antimüllerian hormone and retrieved oocytes. Fertil Steril. juill 2012;98(1):141 - 4.

[11] Lekovich J, Lobel ALS, Stewart JD, Pereira N, Kligman I, Rosenwaks Z. Female patients with lymphoma demonstrate diminished ovarian reserve even before initiation of chemotherapy when compared with healthy controls and patients with other malignancies. J Assist Reprod Genet. mai 2016;33(5):657- 62 .

[12] Cakmak H, Katz A, Cedars MI, Rosen MP. Effective method for emergency fertility preservation: random-start controlled ovarian stimulation. Fertil Steril. déc 2013;100(6):1673 - 80.

[13] Cakmak H, Rosen MP. Random-start ovarian stimulation in patients with cancer. Curr Opin Obstet Gynecol. juin 2015;27(3):215- 21.

[14] Cobo A, Garcia-Velasco JA, Domingo J, Remohí J, Pellicer A. Is vitrification of oocytes useful for fertility preservation for age-related fertility decline and in cancer patients? Fertil Steril. mai 2013;99(6):1485- 95.

[15] Kiwoong Ko, Min-Jung, Kwon, Hee-Yeon Woo, and Hyosoon Park, van Gammeren AJ1, van Gool N, de Groot MJ, Cobbaert CM. Evaluation of Analytical Performance of the Cobas 8000 Analyzer Series Module e602. Lab Med Qual Assur. avr 2015;(37):101- 9.

[16] Cobo A, García-Velasco JA, Coello A, Domingo J, Pellicer A, Remohí J. Oocyte vitrification as an efficient option for elective fertility preservation. Fertil Steril. mars 2016;105(3):755-764.e8.

[17] Smith V, Osianlis T, Vollenhoven B. Prevention of Ovarian Hyperstimulation Syndrome: A Review. Obstet Gynecol Int. 2015;2015:1 - 10.

[18] Agarwal A, Newton RA. The effect of cancer on semen quality after cryopreservation of sperm. Andrologia. 24 avr 2009;23(5):329- 32.

[19] Paradisi R, Vicenti R, Macciocca M, Seracchioli R, Rossi S, Fabbri R. High cytokine expression and reduced ovarian reserve in patients with Hodgkin lymphoma or non-Hodgkin lymphoma. Fertil Steril. oct 2016;106(5):1176- 82. 
[20] Das M, Shehata F, Moria A, Holzer H, Son W-Y, Tulandi T. Ovarian reserve, response to gonadotropins, and oocyte maturity in women with malignancy. Fertil Steril. juill 2011;96(1):122- 5 .

[21] Quintero RB, Helmer A, Huang JQ, Westphal LM. Ovarian stimulation for fertility preservation in patients with cancer. Fertil Steril. févr 2010;93(3):865- 8.

[22] Alvarez RM, Ramanathan P. Fertility preservation in female oncology patients: the influence of the type of cancer on ovarian stimulation response. Hum Reprod. 1 juill 2016; dew158.

[23] M . von Wolff T. Bruckner, T. Strowitzki A. Germeyer. Fertility preservation ovarian response to freeze oocytes is not affected by different malignant diseases an analysis of 992 stimulations.docx. Journal of Assisted Reproduction and Genetics, Volume 35, Issue 9, pp 1713-1719; 2018.

[24] Kim JH, Kim SK, Lee HJ, Lee JR, Jee BC, Suh CS, et al. Efficacy of Random-start Controlled Ovarian Stimulation in Cancer Patients. J Korean Med Sci. 2015;30(3):290.

[25] Sonigo C, Comtet M, Duros S, Sifer C, Sermondade N, Grynberg M. Antral follicle responsiveness to FSH, assessed by the follicular output rate (FORT), is altered in Hodgkin's lymphoma when compared with breast cancer candidates for fertility preservation. J Assist Reprod Genet. janv 2018;35(1):91- 7 .

\section{Annexes}

Figure 1: Patient Flow chart 


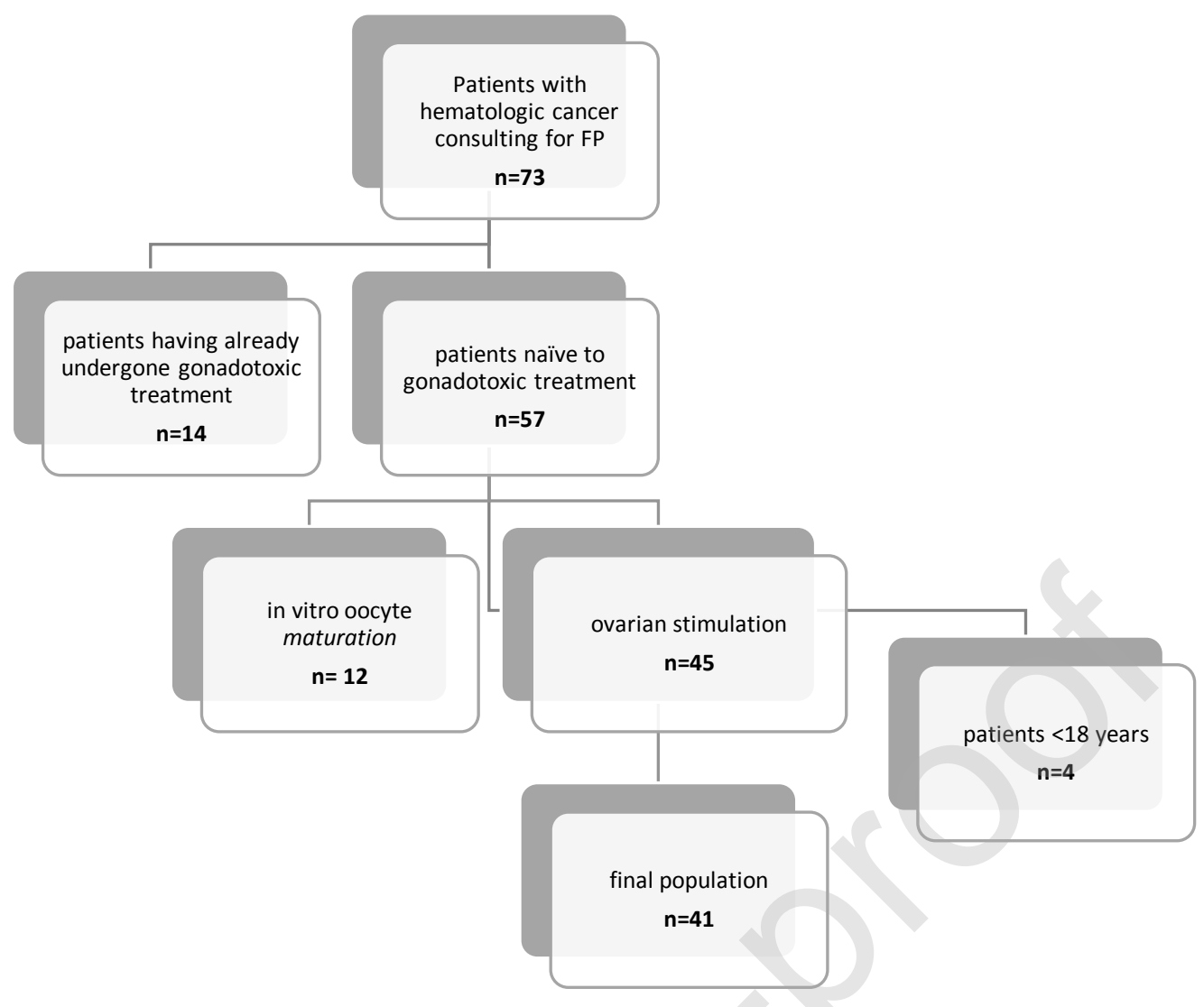

Table 1: Type of hematologic cancer and chemotherapy

\begin{tabular}{|c|c|c|c|}
\hline Hematologic malignancy & Pat & & $\begin{array}{l}\text { Chemotherapy } \\
13 \text { ABVD } \\
8 \text { BEACOP } \\
1 \text { R-CHOP } \\
8 \text { Unknown }\end{array}$ \\
\hline \multirow[t]{5}{*}{ Hodgkin’s Lymphoma } & \multirow[t]{5}{*}{30} & Stage $1: 4$ & \multirow{5}{*}{$\begin{array}{l}13 \text { ABVD } \\
8 \text { BEACOP } \\
1 \text { R-CHOP } \\
8 \text { Unknown }\end{array}$} \\
\hline & & Stage $2: 6$ & \\
\hline & & Stage $3: 3$ & \\
\hline & & Stage $4: 3$ & \\
\hline & & Unknown : 14 & \\
\hline Non-Hodgkin's Lymphoma & \multicolumn{2}{|l|}{9} & $\begin{array}{l}2 \text { BEACOP } \\
5 \text { RCHOP } \\
3 \text { Unknown }\end{array}$ \\
\hline Acute Myeloid Leukemia & \multicolumn{2}{|l|}{1} & Daunorubicine $90+$ Cytarabine \\
\hline Chronic Myeloid Leukemia & \multicolumn{2}{|l|}{1} & Unknown \\
\hline
\end{tabular}


Table 2: Patient characteristics

\begin{tabular}{|c|c|c|c|c|}
\hline Variable & Global (N=158) & FP $(N=41)$ & OD $(\mathrm{N}=117)$ & $\mathbf{P}$ \\
\hline $\begin{array}{l}\text { Age } \\
\text { (Years) }\end{array}$ & $32(18 ; 38)$ & $24(18 ; 37)$ & $33(23 ; 38)$ & $\mathrm{p}<0.0001(\mathrm{~W})$ \\
\hline $\begin{array}{l}\text { BMI } \\
\left(\mathrm{Kg} / \mathrm{m}^{2}\right)\end{array}$ & $\begin{array}{l}(150) \\
22.9(16 ; 45)\end{array}$ & $\begin{array}{l}(39) \\
21.48(16 ; 45)\end{array}$ & $\begin{array}{l}(111) \\
23.4(16 ; 40.1)\end{array}$ & $\mathrm{p}=0.0219(\mathrm{~W})$ \\
\hline $\begin{array}{l}\text { AMH } \\
\mathrm{ng} / \mathrm{mL}\end{array}$ & $\begin{array}{l}(155) \\
3.5(0.1 ; 19)\end{array}$ & $\begin{array}{l}(38) \\
3.4(0.1 ; 11)\end{array}$ & $\begin{array}{l}(117) \\
3.5(0.6 ; 19)\end{array}$ & $\mathrm{p}=0.4353(\mathrm{~W})$ \\
\hline ACF-ACF & $\begin{array}{l}(120) \\
20(4 ; 56)\end{array}$ & $\begin{array}{l}(34) \\
20(4 ; 41)\end{array}$ & $\begin{array}{l}(86) \\
20(5 ; 56)\end{array}$ & $\mathrm{p}=0.4806(\mathrm{~W})$ \\
\hline $\begin{array}{l}\text { FSH starting doses } \\
\text { (UI) }\end{array}$ & $175(87.5 ; 450)$. & $225(125 ; 450)$ & $150(87.5 ; 337.5)$ & $\mathrm{p}<0.0001^{*}$ \\
\hline \multicolumn{5}{|c|}{$\begin{array}{l}\text { FP: fertility preservation patients with hematologic cancer, OD: oocyte donors, BMI : Body Mass Index, AMH : anti mullerian hormone, ACF AFC : antral } \\
\text { follicle count } \\
\text { Values are expressed as (population) median (min ; max) } \\
\text { (W) Mann-Whitney Wilcoxon's test } \\
\text { *after age, BMI and AMH adjustment according to ANCOVA }\end{array}$} \\
\hline
\end{tabular}

Table 3: $\mathrm{COH}$ characteristics and outcomes after adjusting for age, sex, BMI and starting rFSH dose according to ANCOVA

\begin{tabular}{|c|c|c|c|c|}
\hline Variable & Global $(\mathrm{N}=158)$ & $\mathrm{FP}(\mathrm{N}=41)$ & OD $(\mathrm{N}=117)$ & $\mathbf{P *}$ \\
\hline $\begin{array}{l}\text { Number of oocytes } \\
\text { retrieved }\end{array}$ & $11(0 ; 49)$ & $12(0 ; 49)$ & $11(0 ; 29)$ & 0.0468 \\
\hline $\begin{array}{l}\text { Number of frozen } \\
\text { mature oocytes }\end{array}$ & $9(0 ; 45)$ & $10(0 ; 45)$ & $8(0 ; 22)$ & 0.0055 \\
\hline $\begin{array}{l}\text { Percentage } \\
\text { maturity }\end{array}$ & $\begin{array}{l}\theta .8(0 ; 1) 80 \%(0 ; \\
100)\end{array}$ & $\begin{array}{l}0.82(0 ; 1) 82 \%(0 ; \\
100)\end{array}$ & $\begin{array}{l}\theta .80(0 ; 1) 80 \%(0 ; \\
100)\end{array}$ & 0.2262 \\
\hline $\begin{array}{l}\text { Number of dominant } \\
\text { follicles }>14 \mathrm{~mm}\end{array}$ & $9(1 ; 44)$ & $11(3 ; 33)$ & $8(1 ; 44)$ & 0.1309 \\
\hline $\begin{array}{l}\text { Number of mature } \\
\text { oocytes / number of } \\
\text { dominant follicles }\end{array}$ & $0.91(0 ; 9)$ & $0.80(0 ; 3.67)$ & $1(0 ; 9)$ & 0.1253 \\
\hline $\begin{array}{ll}\begin{array}{l}\text { Exogenous } \\
\text { administered }\end{array} & \text { rFSH }\end{array}$ & $2000(400 ; 6300)$ & $2950(1600 ; 6300)$ & $1800(400 ; 5650)$ & 0.0766 \\
\hline $\begin{array}{l}\text { Maximum estradiol } \\
\text { level dOt }\end{array}$ & $1242.5(225 ; 8528)$ & $1321(322 ; 8528)$ & $1212(225 ; 4796)$ & 0.2989 \\
\hline $\begin{array}{l}\text { Duration of } \\
\text { stimulation (days) }\end{array}$ & $11(4 ; 14)$ & $13(8 ; 18)$ & $11(4 ; 14)$ & 0.3679 \\
\hline
\end{tabular}

